\title{
Ketone bodies as markers for Type 1 (insulin-dependent) diabetes and their value in the monitoring of diabetic control
}

\author{
Y.Harano, K. Kosugi, T.Hyosu, M. Suzuki, H. Hidaka, A. Kashiwagi, S. Uno ${ }^{1}$ and Y. Shigeta \\ The Third Department of Medicine, Shiga University of Medical Science, Ohtsu, Shiga, and ${ }^{\dagger}$ Sanwa Kagaku Kenkyusho, Nagoya, Japan
}

\begin{abstract}
Summary. Serum levels of acetoacetate, 3-hydroxybutyrate and the 3-hydroxybutyrate/acetoacetate ratio were determined in Type 1 (insulin-dependent) and Type 2 (non-insulindependent) diabetic patients by a new sensitive method. Efforts were made to differentiate Type 1 and Type 2 diabetes by serum levels of ketone bodies and to determine whether their measurement is a useful way of monitoring diabetic control. In Type 2 diabetes, serum levels of total ketone bodies did not exceed $2.0 \mathrm{mmol} / \mathrm{l}$ even if the patients were untreated or poorly controlled. In Type 1 diabetic subjects, treated with once or twice daily injections of insulin, morning serum levels of acetoacetate, 3-hydroxybutyrate and total ketone bodies were significantly elevated by four-, ten- and sevenfold, respectively. In Type 2 diabetic subjects treated with diet or sulphonylu-
\end{abstract}

reas, serum levels of 3-hydroxybutyrate were highest before breakfast, next highest before dinner and decreased after each meal. The changes were roughly inversely proportional to serum insulin levels. In addition, insulin treatment normalized fasting serum levels of ketone bodies better than diet or sulphonylurea treatment. Acetoacetate was also significantly increased in both types of diabetes to a lesser extent, but no apparent diurnal thythm was observed. Determination of serum levels of ketone bodies is useful for the diagnosis of Type 1 diabetes (those with total ketone bodies $>2 \mathrm{mmol} / \mathrm{l}$ ) and for detecting insufficient insulin therapy.

Key words: Ketone bodies, acetoacetate, 3-hydroxybutyrate, Types 1 and 2 diabetes, ketosis.
Proneness to ketosis is an important measure for differentiating Type 1 (insulin-dependent) and Type 2 (noninsulin-dependent) diabetes [1, 2]. Routine tests for ketone bodies (nitroprusside reaction) only detect acetoacetate (AcAc), and acetone to a lesser degree, but not 3-hydroxybutyric acid (3-OHBA), the major ketone body which is increased in poorly controlled diabetes [3].

Ketone bodies are increased also in the sera of healthy diabetic subjects $[4,5]$. Therefore, quantification of serum levels may be clinically important for assessing control in both types of diabetes.

We have developed a sensitive and simplified method for the determination of AcAc and 3-OHBA. With this method, we have tried to assess whether quantification of serum levels of ketone bodies is useful (a) to differentiate Type 1 from Type 2 diabetes, and (b) to monitor diabetic control.

\section{Subjects and methods}

\section{Subjects}

The 91 normal subjects were aged between 18 and 65 years. The diabetic subjects were classified into Type 1 and Type 2 diabetes accord- ing to the National Diabetes Data Group (1) and WHO Expert Commitee [2]. Overnight fasting blood was obtained from 117 treated Type 1 diabetic subjects, aged 7-20 years. All had urinary C-peptide reactivity excretion $<10 \mu \mathrm{g} /$ day. Haemoglobin $A_{1}$ levels were elevated (mean $\pm \mathrm{SEM}, 12.1 \pm 0.3 \%, \mathrm{n}=53$; upper limit of our normal range: $8 \%$ ). All had been treated with intermediate-type insulin (mean $\pm S E M, 27 \pm 1.4 \mathrm{U}$ ) before breakfast. Eighteen received additional intermediate-type insulin $(13.4 \pm 2.7 \mathrm{U})$ before dinner. Twentytwo subjects received short-acting insulin $(6.7 \pm 0.9 \mathrm{U})$ concomitant with the morning intermediate-type insulin. Fourteen adult-onset Type 1 diabetic patients, including four with ketoacidosis, were also included to study the relationship between fasting plasma glucose and serum ketone bodies levels. The other 10 subjects were classified as having Type 1 diabetes on the basis of ketosis-proneness, episode of ketosis and rapid progression to insulin dependency. At least 260 Type 2 diabetic subjects treated or untreated ( 28 subjects) were studied. They had a urinary C-peptide reactivity excretion $>20 \mu \mathrm{g} /$ day (up to a maximum of $80 \mu \mathrm{g} /$ day). One-third had normal glycosylated haemoglobin $\left(\mathrm{HbA}_{1}\right)$ levels $(9.5 \pm 0.25 \%$, mean \pm SEM, $n=91)$. Those who received insulin for diabetic control had previously been on diet or sulphonylurea treatment. They were classified into those on diet, sulphonylureas and insulin, and further divided according to the degree of fasting hyperglycaemia. In most subjects, ketone bodies were determined repeatedly: using a representative stabilized value after 2-4 weeks treatment. Only one value was used for each subject except in severe and untreated subjects whose initial values were also used. Newly diagnosed untreated subjects were analysed with the diet group, since their total calorie intake per day and food composition were similar. The Type 2 diabetic subjects in this study were mostly 
Table 1. Serum ketone bodies levels in juvenile Type 1 diabetic subjects according to fasting plasma glucose levels

\begin{tabular}{|c|c|c|c|c|c|c|}
\hline & $\begin{array}{l}\text { Fasting } \\
\text { plasma } \\
\text { glucose } \\
(\mathrm{mmol} / \mathrm{l})\end{array}$ & $\begin{array}{l}\text { No. } \\
\text { of } \\
\text { subject }\end{array}$ & $\begin{array}{l}\text { Aceto- } \\
\text { acetate } \\
(\mu \mathrm{mol} / 1)\end{array}$ & $\begin{array}{l}\text { 3-Hydroxy- } \\
\text { butyrate } \\
(\mu \mathrm{mol} / \mathrm{l})\end{array}$ & $\begin{array}{l}\text { Total } \\
(\mu \mathrm{mol} / 1)\end{array}$ & $\begin{array}{l}\text { 3-OHBA/AcAc } \\
\text { ratio }\end{array}$ \\
\hline $\begin{array}{l}\text { Normal subjects } \\
\text { Type } 1 \text { diabetic subjects }\end{array}$ & $\begin{aligned}- & \\
\leqslant & 5.6 \\
& 5.6-7.8 \\
& 7.8-11.1 \\
> & 11.1\end{aligned}$ & $\begin{array}{l}91 \\
15 \\
28 \\
24 \\
50\end{array}$ & $\begin{array}{l}41.0 \pm 1.4 \\
113 \pm 11^{\mathrm{b}} \\
149 \pm 9^{\mathrm{b}} \\
148 \pm 13^{\mathrm{b}} \\
203 \pm 13^{\mathrm{b}}\end{array}$ & $\begin{array}{c}34 \pm 2.1 \\
182 \pm 32^{b} \\
261 \pm 35^{b} \\
308 \pm 42^{b} \\
487 \pm 45^{b}\end{array}$ & $\begin{array}{c}74 \pm 2.4 \\
295 \pm 39^{\mathrm{a}} \\
410 \pm 42^{\mathrm{b}} \\
465 \pm 53^{\mathrm{b}} \\
689 \pm 57^{\mathrm{b}}\end{array}$ & $\begin{array}{l}0.91 \pm 0.07 \\
1.6 \pm 0.2^{\mathrm{a}} \\
1.7 \pm 0.2^{\mathrm{a}} \\
2.0 \pm 0.1^{\mathrm{b}} \\
2.2 \pm 0.1^{\mathrm{b}}\end{array}$ \\
\hline Total & $10.4 \pm 0.4$ & 117 & $167 \pm 7^{\mathrm{b}}$ & $357 \pm 25^{b}$ & $524 \pm 32^{\mathrm{b}}$ & $2.0 \pm 0.1^{b}$ \\
\hline
\end{tabular}

Results expressed as mean $\pm \mathrm{SEM}$

a $p<0.02$, b $p<0.001$ versus normal subjects

non-obese (mean \pm SEM percentage ideal weight, $101 \pm 0.02 \%$ ). Those who had been admitted to hospital with ketoacidosis were excluded.

\section{Determination of ketone bodies}

Blood was drawn before breakfast unless otherwise stated. No difference in ketone body concentration was noted for either heparinized plasma or serum. Ketone bodies were stable for a few hours at room temperature while the blood clotted. Ketone bodies were also unchanged when stored for $12 \mathrm{~h}$ as whole blood in a refrigerator $\left(4^{\circ} \mathrm{C}\right)$. Usually ketone bodies were determined on the day of sampling. In some samples, they were determined within 1 week after storage at $-70^{\circ} \mathrm{C}$ (acetoacetate was found to be stable for up to $2-3$ weeks at $-70^{\circ} \mathrm{C}$ ). 3 -Hydroxybutyrate did not change during storage for this period even at $-20^{\circ} \mathrm{C}$.

Acetoacetate was determined by a newly-devised technique [6], using a modification of Salway's method [7]. In the present method, pnitrophenyl-diazonium fluoroborate, which is more stable than the original diazonium salt, was used. In addition, the reaction product was more stable and quantitative. 3-OHBA concentration was calculated from the difference between the total ketone body and AcAc levels. Total concentration was determined in sera after enzymatic conversion of 3-OHBA to AcAc. The morlar extinction coefficient of azocompound at $645 \mathrm{~nm}$ is $33.6 \times 10^{3} \cdot \mathrm{mol}^{-1} \cdot \mathrm{cm}^{-1}$, which is five times greater than NADH. A good correlation was noted between the present and the enzymatic method $(r=0.97-0.99, n=20)$.

Glucose [8], insulin [9], glucagon [10], growth hormone, and lipid levels were determined as described previously [11]. $\mathrm{HbA}_{1}$ was determined by the method of Trivelli et al. [12] and urinary C-peptide reactivity was determined as described by Kuzuya et al. [13].

\section{Chemicals and reagents}

Lithium acetoacetate was obtained from Sigma, St. Louis, Missouri, USA. p-Nitrophenyl diazonium fluoroborate was synthesized [14], but is now available from Sanwa Kagaku Kenkyusho, Nagoya, Japan. 3-Hydroxybutyrate was purified from pseudomonas lemoignei with specific activity over $40 \mathrm{U} / \mathrm{mg}$ protein, which is also available from Sanwa Kagaku Kenkyusho.

\section{Statistical methods}

The Student's t-test was used to analyse the significance of the difference. Paired t-test was used to evaluate post-prandial changes of blood glucose, serum insulin and ketone bodies (Fig. 4). Correlation coefficient $(r)$ and probability of rejection of null hypothesis $(p)$ are shown. Equation of linear regression was also calculated for the relationships between blood glucose and ketone bodies levels.

\section{Results}

The serum levels of ketone bodies in juvenile Type 1 diabetic patients, according to fasting plasma glucose levels are shown in Table 1 . The Type 1 diabetic subjects were split into four groups according to fasting plasma glucose levels. Serum levels of AcAc, 3-OHBA and total ketone bodies were all elevated by five-, fourteen- and ninefold in the diabetic subjects with fasting plasma glucose $>11.1 \mathrm{mmol} / 1$ (Table 1$)$. The degree of elevation, especially for 3-OHBA, was roughly proportional to the fasting plasma glucose levels, and therefore the 3-OHBA/AcAc ratio was significantly increased $(p<$ 0.001 ). Even in those patients with fasting plasma glucose $\leqslant 5.6 \mathrm{mmol} / 1$, AcAc, 3-OHBA and total ketone bodies were increased by $2.7-, 5.4-$ and fourfold, respectively. Thus, in spite of insulin treatment, most of the Type 1 diabetic subjects exhibited ketonaemia.

\section{Relationship between fasting plasma glucose and serum total ketone bodies levels in Type I diabetes}

A correlation was noted between fasting plasma glucose and serum levels of total ketone bodies $(r=0.47, p<$ 0.001 , Fig. 1). Seven subjects, whose total ketone bodies were $>1.8 \mathrm{mmol} / 1$, were adult Type 1 diabetic subjects. Among them, four, whose total ketone bodies exceeded $3.0 \mathrm{mmol} / 1$, were untreated or without insulin for a few days and were ketoacidotic on admission. The $3-\mathrm{OH}-$ $\mathrm{BA} / \mathrm{AcAc}$ ratio ranged from 1.5 to 5.8 in these subjects. The major increase of serum ketone bodies was attributable to 3-OHBA, with AcAc increased to a lesser degree. The remaining subjects were treated with insulin (Fig. 1).

In Type 1 diabetes, ketone bodies increased according to the degree of hyperglycaemia.

\section{Serum ketone bodies levels and 3-OHBA/AcAc ratio in Type 2 diabetes in relation to graded fasting hyperglycaemia}

In poorly-controlled Type 2 patients, whose plasma glucose exceeded $11.1 \mathrm{mmol} / \mathrm{l}$, serum levels of $\mathrm{AcAc}$, 


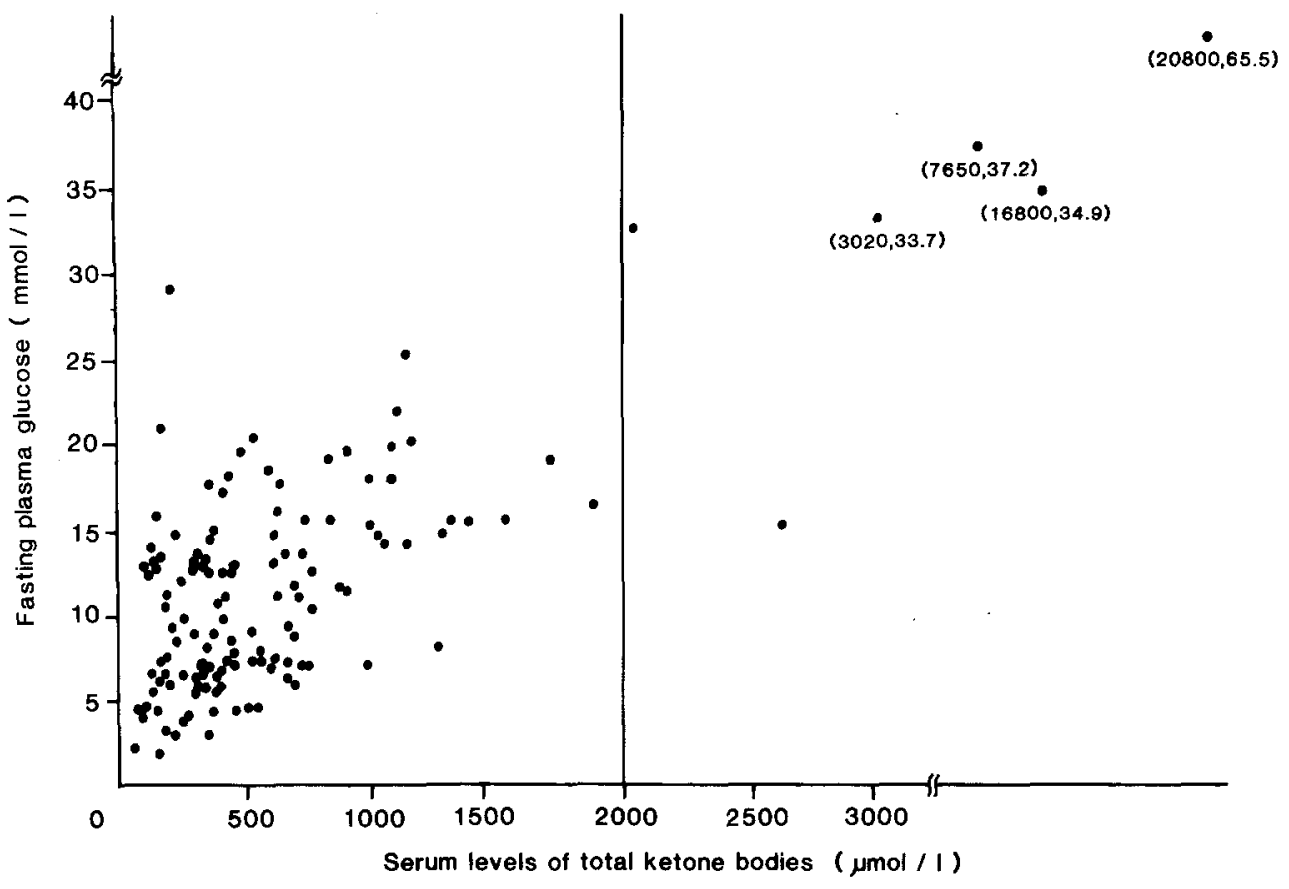

Fig. 1. Relationship between fasting plasma glucose and serum total ketone bodies levels in 131 Type 1 diabetic patients. The vertical line at $2000 \mu \mathrm{mol} / 1$ indicates the cut off point for proneness to ketosis. Figures in parentheses indicate actual values of total ketone bodies and glucose. (Correlation coefficient, $\mathrm{r}=0.47, \mathrm{p}<0.001$, regression equation, $\mathrm{Y}=4.0 \mathrm{X}+10.6$ )

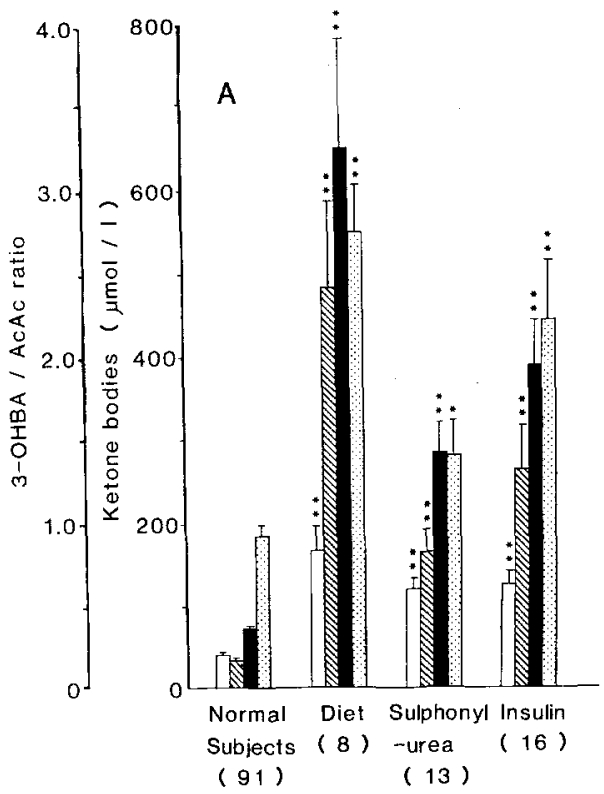

B

c
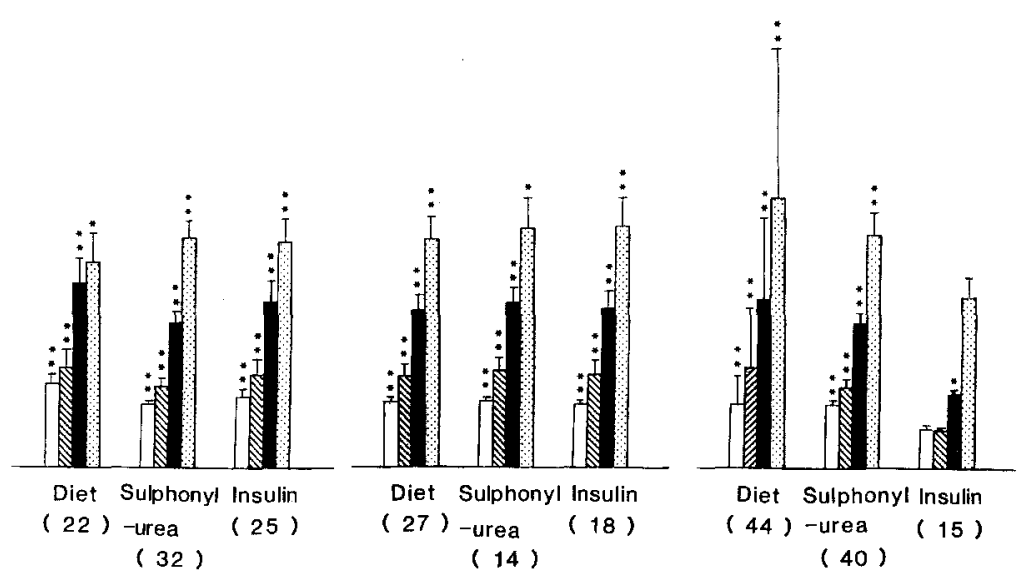

Fig. 2. A-D Serum levels of individual ketone bodies in relation to fasting plasma glucose levels in normal subjects and Type 2 diabetic patients treated with diet, sulphonylureas or insulin (numbers of patients given in parentheses). A Poorly controlled diabetic patients (fasting plasma glucose $>11.1 \mathrm{mmol} / 1)$; B fairly well controlled diabetic patients $(11.1 \geqq$ fasting plasma glucose $>7.8 \mathrm{mmol} / \mathrm{l})$; C well controlled diabetic patients (7.8 $\geqq$ fasting plasma glucose $>6.1 \mathrm{mmol} / 1$ ); D strictly controlled diabetic patients (fasting plasma glucose $\leqq 6.1 \mathrm{mmol} / \mathrm{l}$ ). Bars indicate mean +SEM; $\square$ AcAc; 3-OHBA; $\square$ total ketone bodies; 3 -OHBA/AcAc ratio. ${ }^{*} p<0.05 ;{ }^{* *} p<0.01$ versus normal subjects

3-OHBA and the 3-OHBA/AcAc ratio were all significantly elevated by two- to tenfold, whether on diet, sulphonylureas or insulin treatment $(p<0.01$; Fig. 2A). Since the elevation of 3-OHBA was greater than the AcAc rise, the 3-OHBA/AcAc ratio was increased. Mean fasting plasma glucose levels did not differ except in the diet group whose fasting plasma glucose was $2.8 \mathrm{mmol} / 1$ higher than the other two groups.

In Type 2 diabetic subjects, whose plasma glucose ranged from 7.8 to $11.1 \mathrm{mmol} / \mathrm{l}$, serum levels of individ- ual ketone bodies increased two- to fivefold in those on diet, sulphonylureas or insulin treatment (Fig. 2B). The ratio was always greater than in control subjects. In those whose fasting plasma glucose was between 6.1 and $7.8 \mathrm{mmol} / \mathrm{l}$, serum levels of AcAc increased twofold, and 3-OHBA by two- to fivefold (Fig. 2C). In strictly-controlled diabetic subjects (fasting plasma glucose $\leqslant 6.1 \mathrm{mmol} / \mathrm{l}$ ), only individual serum ketone bodies were normal in the insulin-treated group: this was not the case in the sulphonylurea- or diet-treated 


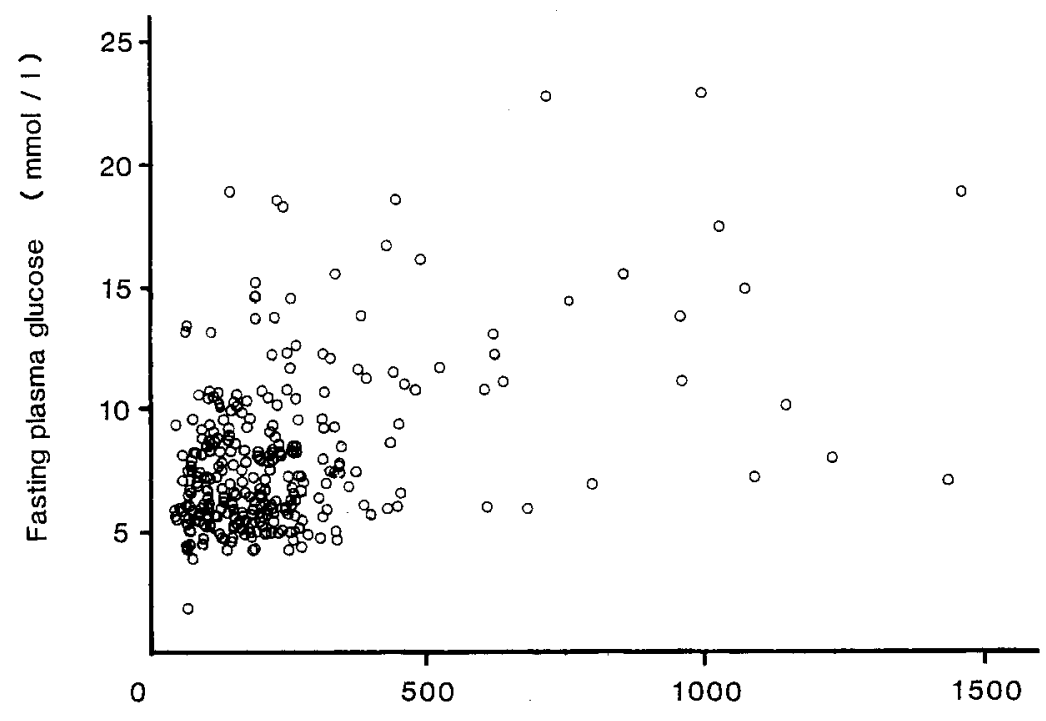

Serum levels of total ketone bodies ( $\mu \mathrm{mol} / 1$ )
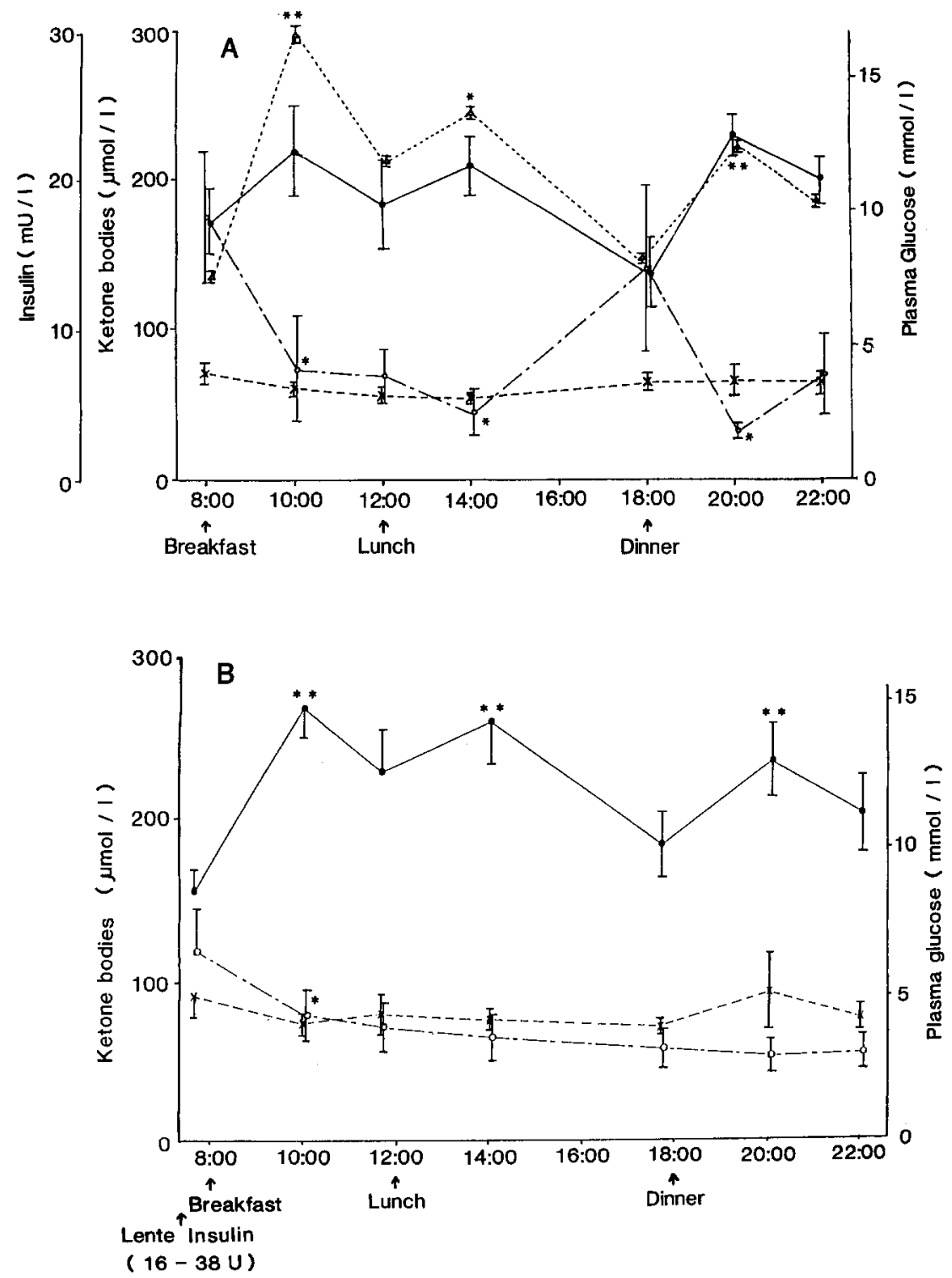

Fig. 3. The relationship between fasting plasma glucose and serum total ketone bodies levels in 281 Type 2 diabetic patients with or without treatment $(r=0.45$, $p<0.001, \mathrm{Y}=0.007 \mathrm{X}+6.4)$
Fig. $4 \mathrm{~A}$ and $\mathrm{B}$. The diurnal changes of serum ketone bodies levels in Type 2 diabetic patients on diet, sulphonylureas or insulin treatment. $\Delta---\Delta:$ serum insulin; : blood glucose; $\mathrm{O}--\mathrm{O}: 3-\mathrm{OHBA}$ and $x---x:$ AcAc. Bars indicate mean \pm SEM. A Type 2 diabetic subjects $(n=17)$ treated by diet or sulphonylureas, B Type 2 diabetic subjects $(n=19)$ treated with insulin. ${ }^{*} p<0.05, \quad * * p<0.025$ versus pre-prandial value 
groups (Fig. 2D). Fasting plasma glucose levels were not significantly different between the three groups. Insulin treatment seemed to be most efficient in normalizing serum ketone bodies levels in Type 2 diabetes.

\section{Relationship between fasting plasma glucose and serum total ketone bodies levels in Type 2 diabetic subjects with or without treatment}

Serum levels of total ketone bodies were plotted against fasting plasma glucose levels in Type 2 diabetic subjects with or without treatment (Fig. 3). A correlation was observed between fasting glucose and serum levels of total ketone bodies $(r=0.45, p<0.001$; Fig. 3). Even in those with untreated diabetes, serum levels of total ketone bodies were $<2.0 \mathrm{mmol} / \mathrm{l}$. Mild ketonaemia, observed in subjects with plasma glucose $<10 \mathrm{mmol} / \mathrm{l}$, was most probably attributable to calorie restriction.

\section{Diurnal changes of serum levels of ketone bodies in Type 2 diabetic subjects on diet, sulphonylureas or insulin treatment}

In diabetic subjects on diet or sulphonylurea treatment, nearly mirror image diurnal changes were noted between serum levels of 3-OHBA and glucose or insulin. 3-OHBA levels were highest before breakfast or dinner when blood glucose and insulin reached their nadir, and decreased significantly after meals (Fig. 4A). Diurnal changes of AcAc were not observed but were slightly high before breakfast. In the insulin-treated subjects, 3-OHBA was highest before breakfast with a gradual decrease in the evening (Fig. 4B). In this group, the postprandial reduction of ketone bodies was not observed in spite of hyperglycaemia after meals. This was thought to be attributable to lack of endogenous insulin secretion. Therefore, insulin seems to play a major role in the diurnal changes of serum 3-OHBA levels.

\section{Discussion}

Ketonaemia is one of the commonest metabolic abnormalities in diabetes $[4,5]$. In all Type 2 diabetic subjects studied here, total ketone bodies were below $2.0 \mathrm{mmol} / 1$ even if the patients were untreated or poorly controlled. We have noted a transient ketonaemia in Type 2 diabetes on an extremely low calorie diet (800 calories/day). Therefore certain conditions, such as extreme diet, exercise, stress or infection, might cause ketonaemia. Otherwise, ketone bodies seem rarely to exceed $2.0 \mathrm{mmol} / 1$ in Type 2 diabetic subjects. In Type 1 diabetes, even in those who were treated with insulin, serum ketone bodies were elevated several fold, and in decompensated state up to $20 \mathrm{mmol} / \mathrm{l}$.

Since the major ketone body which increases in blood is 3-OHBA, routine urine tests with the nitroprusside reaction are inadequate to evaluate ketonaemia. At a recent summer camp held in Osaka, out of 47 juvenile Type 1 diabetic subjects, only eight (5\%) exhibited ketonuria, while serum 3-OHBA levels were elevated in 25 $(>0.2 \mathrm{mmol} / \mathrm{l} ; 53 \%)$. In addition, serum 3 -OHBA was increased above $2 \mathrm{mmol} / \mathrm{l}$ in four subjects who were not ketonuric by routine tests [15].

The degree of ketonaemia and the increased 3-OH$\mathrm{BA} / \mathrm{AcAc}$ ratio were roughly parallel to fasting plasma glucose levels. A significant correlation was observed between total ketone bodies and the 3-OHBA/AcAc ratio ( $r=0.5, p<0.001, n=200$ for Type 2, and $r=0.69$, $p<0.001, n=82$ for Type 1 diabetic subjects). The preferential elevation of 3-OHBA in sera and the early reduction after insulin therapy have also been noted by other investigators in a limited number of subjects $[3,5]$. However, the present study has demonstrated clearly the preferential elevation of 3-OHBA with insulinopenia in the both types of diabetes.

Ketonaemia was most prominent in the morning followed by another peak before dinner. Post-prandially, 3-OHBA decreased in those who had an endogenous insulin response, but not in those on insulin treatment (single dose of intermediate-type insulin). This indicates that hyperglycaemia per se cannot suppress ketonaemia. Insulin seems to be the most important factor for the diurnal changes of 3-OHBA. In normal subjects, Wildenhoff noted a peak rise of ketone bodies at midnight followed by a peak before dinner or breakfast [16]. In addition, growth hormone was not attributed as a trigger for the rise of ketone bodies [17]. In juvenile Type 1 diabetic patients, serum glucagon levels were previously found to be elevated before breakfast [15]. Glucagon and cortisol may play a role in accelerating morning ketonaemia, especially for 3-OHBA $[15,18]$. A morning rise of these insulin-antagonistic hormones may be attributable to insufficient levels of insulin in the early morning.

In Type 2 diabetes those with fasting plasma glucose below $6.1 \mathrm{mmol} / 1$ exhibited normal individual ketone bodies in the insulin-treated group, but not in the dietary or sulphonylurea-treated groups. This indicates that in subjects on diet or sulphonylureas, normoglycaemia was attained at the expense of increased fat mobilization and oxidation. Insulin seems to be most efficient in normalizing these metabolic derangements. Serum ketone bodies levels, therefore, serve as a metabolic marker to monitor the derangement of fuel metabolism, which is characterized by increased fatty acid oxidation. Dissociated responses of serum glucose and ketone bodies after insulin treatment is more prominent in Type 1 diabetes. Even in those whose fasting plasma glucose fell below $5.6 \mathrm{mmol} / 1$, a marked elevation of ketone bodies was noted. When using a typical insulin regimen (single or twice daily injection of intermediate insulin) in juvenile Type 1 diabetes, the morning level of serum insulin seemed to be insufficient. In Type 2 diabetes, residual pancreatic B-cell function may supply sufficient basal levels of insulin. High morning levels of 
ketone bodies may reflect morning insulinopenia [19]. Therefore, determination of ketone bodies may be a useful metabolic marker to estimate adequacy of insulin doses. Some investigators have already used 3-OHBA, determined by the enzymatic method as a metabolic marker in Type 1 diabetes [18, 20]. However, their normal ranges were higher than ours.

Since haemoglobin $A_{1}$ was increased in most of our Type 1 diabetic subjects, residual metabolic derangement may have contributed to the observed ketonaemia in normoglycaemic subjects. Hepatic esterification of non-esterified fatty acid may be diminished in these subjects due to insufficient insulin action, contributing to the overproduction of ketone bodies.

Non-esterified fatty acid may also serve as a metabolic marker, but it fluctuates little $(0.2-2 \mathrm{mmol} / \mathrm{l}) \mathrm{com}$ pared with ketone bodies $(0.05-20 \mathrm{mmol} / \mathrm{l})$. There was better correlation between non-esterified fatty acid and total ketone bodies in Type $1(r=0.7, p<0.001, n=44)$ compared with Type 2 diabetes $(r=0.33, p<0.001$, $n=221$ ). Ketonaemia also reflects the ketogenic activity of the liver, which is accelerated by glucagon [21], with enhanced lipolysis in adipose tissue.

Post-prandial serum levels of ketone bodies ( $2-3 \mathrm{~h}$ ) were less remarkable in both types of diabetes. Although values were still greater than normal, detection of such low levels of ketone bodies $(<100 \mu \mathrm{mol} / \mathrm{l})$ requires a sensitive and accurate assay. Although it is best to determine total ketone bodies, 3-OHBA increases most in diabetic subjects, and this may be useful as a routine test. In addition, the 3-OHBA/AcAc ratio may reflect altered tissue redox potential and give some insight into deranged tissue metabolism. Further studies are necessary to elucidate the clinical implication of the increased 3-OHBA/AcAc ratio.

Determination of ketone bodies, especially before breakfast, may serve as a metabolic marker of insulinopenia and subtle derangement of fatty acid and intermediary metabolism.

Acknowledgements. We are grateful to Drs. M.Hoshi of Koseinenkin Hospital, K. Izumi of Osaka National Hospital and G. Ishiki of Osaka City University for enabling us to perform the clinical study at the summer camp sponsored by the Osaka Diabetes Association.

\section{References}

1. National Diabetes Data Group (1979) Classification and diagnosis of diabetes mellitus and other categories of glucose intolerance. Diabetes 28: 1039-1057

2. WHO Expert Committee on Diabetes Mellitus (1980). Second report, Technical Report Series 646, Geneva

3. Keisberg RA (1978) Diabetic ketoacidosis: new concepts and trends in pathogenesis and treatment. Ann Int Med 88: 681-695

4. Werk Jr EE, Knowles HC (1960) The blood ketone and plasma free fatty acids concentration in diabetic and normal subjects. Diabetes 10: 22-32
5. MacGillivray MH, Li PK, Lee JT, Mills BJ, Voorhess ML, Putman TI, Schaefer PA (1981) Elevated plasma $\beta$-hydroxybutyrate concentrations without ketonuria in healthy insulin-dependent diabetic patients. J Clin Endocrinol Metab 52: 982-987

6. Harano Y, Kosugi K, Hyosu T, Uno S, Ichikawa Y, Shigeta Y (1983) Sensitive and simplified method for the differential determination of serum levels of ketone bodies. Clinica Chim Acta 134: 327-337

7. Salway JG (1969) The simultaneous determination of acetoacetate and glucose in capillary blood. Clin Chim Acta 25: 109-116

8. Hoffman WS (1973) A rapid photoelectric method for the determination of glucose in blood and urine. J Biol Chem 120:51-55

9. Yalow RS, Glick SM, Roth J, Berson SA (1965) Plasma insulin and growth hormone levels in obesity and diabetes. Ann NY Acad Sci 131: 357-373

10. Imagawa $K$, Nishino $T$, Shin $T$, Uegata $S$, Eyanaihara $C$, Yanaihara N (1979) Production of anti-glucagon sera with a C-terminal fragment of pancreatic glucagon. Endocrinol Japon 26: 123-132

11. Harano T, Ohgaku S, Kosugi K, Yasuda H, Nakano T, Kobayashi M, Hidaka H, Izumi K, Kashiwagi A, Shigeta Y (1893) Clinical significance of altered insulin sensitivity in diabetes mellitus assessed by glucose, insulin and somatostatin infusion. J Clin Endocrinol Metab 52: 982-987

12. Trivelli LA, Ranney HM, Lai HT (1971) Hemoglolin components in patients with diabetes mellitus. New Engl J Med 284: 353-357

13. Kuzuya T, Mastuda A, Sakamoto Y (1978) C-peptide immunoreactivity in urine. Diabetes 27 (Suppl 1): 210-215

14. Sterkey EB (1943) P-dinitrobenzene. Organic Synthesis. Coll 2: $225-228$

15. Harano Y, Kojima H, Suzuki M, Kashiwagi A, Hyosu T, Hidaka H, Hoshi M, Izumi K, Shigata Y (1984) Serum levels of ketone bodies as metabolic markers monitoring diabetic control in Type 1 diabetic subjects. Med J Osaka Univ (in press)

16. Wildenhoff KE (1972) Diurnal variations in the concentrations of blood acetoacetate, 3-hydroxybutyrate and glucose in normal persons. Acta Med Scand 191: 303-306

17. Wildenhoff KE, Hohansen JP, Karstoft H, Yde H, Sorensen S (1974) Diurnal variations in the concentrations of blood acetoacetate and 3-hydroxybutyrate. Acta Med Scand 195: 25-2818

18. MacGillivray MH, Voorhess ML, Putnam TI, Li PK, Schaefer PA, Bruck E (1982) Hormone and metabolic profiles in children and adolescent with Type I diabetes mellitus. Diabetes Care 5 (Suppl 1) $38-47$

19. Harano Y, Hidaka H, Suzuki M, Kojima H, Shigeta Y (1984) Importance of determining serum levels of 3-hydroxybutyrate as a metabolic marker of insulinopenia. In: Sakamoto N (ed) Second Japan-Korea symposium on diabetes mellitus. Excerpta Medica, Amsterdam (in press)

20. Dahlquist G, Blom L, Bolme P, Hagenfeldt L, Linggren F, Dersson B, Thalme B, Theorell M, Westin S (1982) Metabolic control in 131 juvenile-onset diabetic patients as measured by $\mathrm{HBA}_{1 \mathrm{c}}$ : relation to age, duration, C-peptide, insulin dose, and one or two insulin injections. Diabetes Care 5:399-403

21. Harano Y, Kosugi K, Kashiwagi A, Akano T, Hidaka H, Shigeta Y (1982) Regulatory mechanism of ketogenesis by glucagon and insulin in isolated and cultured hepatocytes. J Biochem (Tokyo) 91: 1739-1748

Received: 14 October 1982

and in revised form: 6 March 1984

Dr. Yutaka Harano

Third Department of Medicine

Shiga University of Medical Science

Seta, Ohtsu

Shiga 520-21

Japan 